\title{
Reproductive fecundity of Iraqi Awassi ewes immunized against synthetic inhibin-a subunit or steroid-free bovine follicular fluid
}

\author{
Jabbar Abbas Ahmed Al-Sa'aidi',*, Khalisa Khadim Khudair², and Sura Safi Khafaji ${ }^{3, *}$
}

* Corresponding Authors:

Jabbar Abbas Ahmed Al-Sa'aidi

Tel: +964-7801156473, Fax: +964-3664492,

E-mail: jbr20042002@yahoo.com

Sura Safi Khafaji

Tel: +964-7806773097, E-mail: drsura97@yahoo.com

'Department of Physiology and Pharmacology, College of Veterinary Medicine, University of Al-Qadisiyah,

58, Iraq

2 Department of Physiological, Pharmacology and

Biochemistry, College of Veterinary Medicine,

University of Baghdad, 10, Iraq

${ }^{3}$ Department of Animal Production, College of

Agriculture, University of Kerbala, 56, Iraq

ORCID

Jabbar Abbas Ahmed Al-Sa'aidi

https://orcid.org/0000-0003-2022-2287

Khalisa Khadim Khudair

https://orcid.org/0000-0003-3953-7975

Sura Safi Khafaji

https://orcid.org/0000-0003-2062-7970

Submitted Sept 1, 2017; Revised Nov 26, 2017; Accepted Jan 30, 2018
Objective: The present study was conducted to investigate the impacts of active and passive immunization against synthetic inhibin and steroid-free bovine follicular fluid, respectively, on reproductive fecundity out of breeding season in Iraqi Awassi ewes.

Methods: Follicular fluid was aspired from mature bovine follicles, treated with activated charcoal, and used for immunization of male rabbits for obtaining steroid free bovine follicular fluid (SFBFF) antiserum. Forty non-pregnant Awassi ewes were allocated into 4 groups (n $=10$ each). At day 38 of experiment, ewes were treated with intra-vaginal MPA sponge (60 $\mathrm{mg}$ for 12 days). At days 0,28 , and 50, ewes were treated with 4,2, and $2 \mathrm{~mL}$ of normal saline (control; C-ve), 400, 200, and $200 \mu \mathrm{g}$ of ovalbumin (C+ve), 400, 200 and $200 \mu \mathrm{g}$ of inhibin (SI group), respectively, and $4 \mathrm{~mL}$ of normal saline at day 0 , and 4 and $2 \mathrm{~mL}$ of SFBFF antiserum at days 28 and 50, respectively, (AI group). After mating with Awassi rams, pregnancy and embryo number were diagnosed, at day 38 of pregnancy, using ultrasonography. Blood samples were collected at days 30, 60, 90, and 120 of pregnancy, for assessment of estradiol$17 \beta$ (E2) and progesterone (P4) levels. After parturition, numbers of delivered lambs were recorded.

Results: The results revealed significant increase of $\mathrm{P} 4$ and significant decrease of $\mathrm{E} 2$ levels in SI and AI pregnant ewes than controls at days 30, 60, 90, and 120. Newborn number increased significantly in SI and AI treated than control ewes.

Conclusion: Active or passive immunization against endogenous inhibin could augment reproductive fecundity out of breeding season in Iraqi Awassi ewes.

Keywords: Active and Passive Immunization; Inhibin; Follicular Fluid; Superovulation; Awassi Ewes; Reproductive Fecundity

\section{INTRODUCTION}

In spite of predominant severe environmental conditions such as high ambient temperature, the native Iraqi sheep of Awassi breed contributes significantly to meat and wool production [1]. It has been reported that Awassi sheep breed exhibits low reproductive performance, as compared to European breeds [2]. Many researchers attributed this low fertility to a combination of factors such as poor nutrition and management, diseases and high ambient temperature at breeding season [3].

Awassi breed is monotoccus with an ovulation rate of 1 and very low incidence of twinning [4]. To increase fecundity in sheep, many strategies have been followed such as genetic methods including selection of breeding programs, and non-genetic methods including administration of exogenous gonadotropins such as equine chorionic gonadotropin (eCG) [5], and, recently, immunization against endogenous inhibin [6]. Immunoneutralization against endogenous inhibin may be one of the best ways to elevate fertility rate, since superovulation by either active or passive immunization techniques have provided good results 
where ovarian inhibin contributes to the negative feedback regulation of follicle-stimulating hormone (FSH) secretion $[7,8]$.

Inhibins are also involved in the regulation of folliculogenesis through autocrine and/or paracrine control [9], therefore, it has been predicted that immunoneutralization of endogenous inhibin would lead to an increase in pituitary FSH secretion which could promote ovarian hyperstimulation, resulting in an increased ovulation rate. In this regard, inhibin has been viewed as a negative regulator of ovarian follicular development $[9,10]$. This response has been exploited in inhibin-immunized animals in an attempt to neutralize the biological activities of inhibin and to stimulate ovarian follicular development [11], ovulation rate, litter size, and embryo quantity and quality following superovulation [12].

Multiple ovulations have been induced successfully by active and passive immunization against endogenous inhibin in several species such as mice [13], rats [6], hamsters [14], and cows [15]. Chemically synthesized fragments of inhibin [16] have also provided convincing evidence to support this theory and have proved conclusively that immunoneutralization of endogenous inhibin can promote a marked increase (2-4-fold) in ovulation rate. However, very little information is available regarding the impact of inhibin immunization on other critical stages of the reproductive processes at anestus and whether the observed increase ovulation rate is actually reflected by an increase in viable litter size [17].

Based on the previous information, the current study aimed to examine alternative methods to improve ovulation rate in Awassi ewes through the use of active immunoneutralization against inhibin-based peptide immunogens and passive immunoneutralization against endogenous inhibin by rabbit steroid free bovine follicular fluid (SFBFF) antiserum, It is also aimed to determine the effect of inhibin immunization on conception, pregnancy and lambing rates in Awassi ewes out of breeding season.

\section{MATERIALS AND METHODS}

In this study, all animal experiments have been reviewed by Institutional Animal Care and Use Committee (IACUC) of Baghdad University, Iraq, for the care and use of ewes.

\section{Synthetic inhibin}

Synthetic peptides $\left(\mathrm{NH}_{2}\right)$ with a Sequence of chgleldrelvlakvralfldalghppvt $(\mathrm{COOH})$, was synthesized by Bio-synthesis Inc. (Lewisville, TX, USA), as purified synthetic inhibin powder conjugated with ovalbumin (the peptide-to-ovalbumin molar ratio of approximately 20:1).

Steroid-free bovine follicular fluid antiserum

After aspiration of bovine follicular fluid (BFF) from mature ovarian follicles (15 $\mathrm{mm}$ in diameter), which was centrifuged at $8,000 \mathrm{rpm}$ for 15 minute at $4^{\circ} \mathrm{C}$ to remove cellular debris, $10 \mathrm{mg} / \mathrm{mL}$ of activated charcoal was added to the BFF, mixed for 1 hour at $4^{\circ} \mathrm{C}$, and centrifuged at $14,000 \mathrm{rpm}$ for 90 minute at $4^{\circ} \mathrm{C}$ to separate charcoal with steroids, from which SFBFF was obtained. Ten mature male rabbits were injected subcutaneously (sc) for 5 times with $1 \mathrm{~mL}$ of SFBFF (one-week interval). One month after the last injection, blood was collected, centrifuged and antiserum was obtained and kept at $-20^{\circ} \mathrm{C}$ until use.

\section{Animals}

Awassi ewes (aged 30 to 36 months and weighed 50 to 58 $\mathrm{kg}$ ) were housed at night, and allowed free feeding on grass throughout the remaining hours of the day. Indoors, the ewes were supplemented with concentrated feed, multivitamins, wheat straw, water and minerals freely.

\section{Experimental design}

The experiment was conducted out of breeding season, during the period extended from March, 2016 to December, 2016. As illustrated in Table 1, forty non-pregnant mature Awassi ewes were allocated into 4 groups (10 each). At 38th day of the experiment, Awassi ewes were treated with intra-vaginal sponge impregnated with medroxyprogesterone acetate (MPA) for 12 days. First group ewes were treated at days 0, 28, and 50 with subcutaneous injections of 4,2 , and $2 \mathrm{~mL}$ of normal saline, respectively, and served as negative control group (C-ve). Second group of ewes was treated at days 0,28 , and 50 of experiment with sc. injections of 400, 200, and $200 \mu \mathrm{g}$ of ovalbumin, respectively, and served as positive control group $(\mathrm{C}+\mathrm{ve})$. Third group of ewes was treated at days 0,28 , and 50 with sc. injections of 400, 200, and $200 \mu \mathrm{g}$ of synthetic inhibin, respectively, and served as SI treated group (SI). Forth group of ewes was treated at day 0 with sc. injection of $4 \mathrm{~mL}$ of normal saline, and at days 28 and 50 with $4 \mathrm{~mL}$ and $2 \mathrm{~mL}$ of SFBFF antiserum, respectively, and served as the SFBFF antiserum treated group (AI). During the estrus phase, ewes were mated with experienced Awassi rams. Blood samples were collected at 30, 60, 90, and 120 days of gestation. Blood sera were separated and kept at $-22^{\circ} \mathrm{C}$ until hormonal assessment of $\mathrm{E} 2$ and progesterone concentrations using ELISA technique according to the manufacturer' instructions (Wuhan Fine Biological Technology). Pregnancy was diagnosed using ultrasonography by trans-abdominal examination on day 38 of gestation. Feed was held off from the night before, as it is helpful to shrink the rumen to allow better visualization of the uterus. Ultrasound probe was placed to the right side of the abdomen just ahead of the udder using probe $5 \mathrm{MHz}$.

\section{Statistical analysis}

Results were expressed as mean \pm standard deviation. Com- 
Table 1. Time scale of the experimental protocol

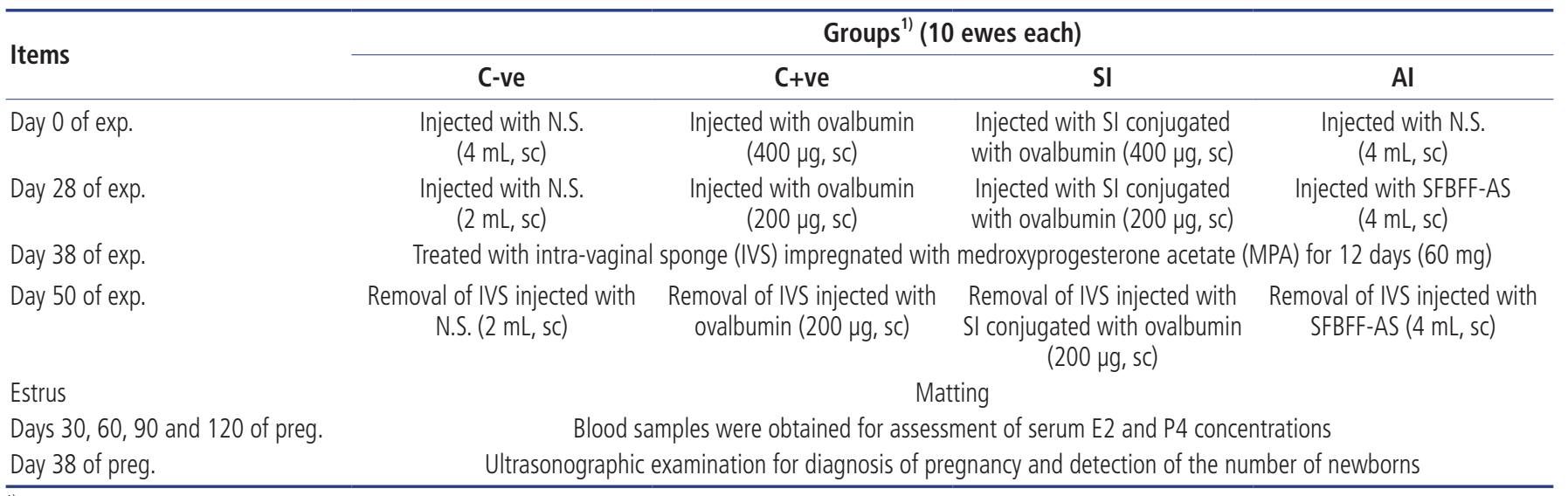

\footnotetext{
${ }^{1)} \mathrm{C}$-ve (negative control group): Awassi ewes injected, at days 0,28 , and 50 of treatment, with 4, 2, and $2 \mathrm{~mL}$ of normal saline, respectively. C+ve (positive control group): Awassi ewes injected, at days 0,28 , and 50 of treatment, with 400, 200, and $200 \mu \mathrm{g}$ of ovalbumin, respectively. SI (synthetic inhibin treated group): Awassi ewes injected, at days 0,28 , and 50 of treatment, with 400,200, and $200 \mu \mathrm{g}$ of synthetic inhibin conjugated with ovalbumin, respectively. Al (steroid free bovine follicular fluid treated group): Awassi ewes injected, at days 0 with $4 \mathrm{~mL}$ of normal saline and at days 28 and 50 with 4 and $2 \mathrm{~mL}$ of SFBFF antiserum, respectively.
}

parisons between groups and periods values were performed using two way analysis of variance (ANOVAII) and NewmanKeuls. Differences were considered to be significant at the level of $\mathrm{p}<0.05$. Statistical analysis was carried out using the GraphPad Prism version-5 (GraphPad Software, Inc. San Diego, CA, USA).

\section{RESULTS}

In the current study, we found that either of the two techniques performed had a positive role for induction of superovulation, elevation of ovulation rates and subsequent twins births in Iraqi Awassi ewes out of breeding season.

\section{Ultrasonographic examination and the number of newborns}

Ultrasonographic (trans-abdominal) examination of pregnant ewes at 38th day of pregnancy, illustrated in Figure 1, showed significant $(\mathrm{p}<0.05)$ increase of embryo number in SI $(2.2 \pm 0.42)$ and $\mathrm{AI}(2.2 \pm 0.42)$ treated group ewes compared either with C-ve $(1.0 \pm 00)$ or $\mathrm{C}+\mathrm{ve}(0.6 \pm 0.52)$, which showed significant $(p<0.05)$ difference when compared with each other. The number of newborns per dam of all experimental groups was compatible with that indicated by ultrasonographic examination (Figure 2).

\section{Weight of lamb at delivery}

In SI, AI, and C+ve group ewes, the delivered newborns revealed insignificant $(\mathrm{p}>0.05)$ difference between each other, but they were significantly $(\mathrm{p}<0.05)$ lower that $\mathrm{C}$-ve group ewe's newborn weight (Figure 3 ).

\section{Serum P4 concentrations}

Serum P4 concentrations revealed no significant $(\mathrm{p}>0.05)$ differences among experimental group ewes at the first and second month of gestation, except $\mathrm{C}$-Ve group ewes which recorded a decreased $(p>0.05)$ level among them. At the third and fourth months of gestation, significant $(\mathrm{p}<0.05)$ elevation of $\mathrm{P} 4$ concentrations were shown in SI and AI group ewes compared with both of control group ewes. In comparison between periods, all group ewes showed gradual significant $(p<0.05)$ elevation of serum P4 concentrations along with the progress of experiment periods, but the elevation in immunized groups (SI and AI) was significantly $(\mathrm{p}<0.05)$ higher than control groups (Figure 4).

\section{Serum E2 concentrations}

As illustrated in Figure 5, serum E2 concentrations revealed no significant $(p>0.05)$ differences among experimental group ewes at the first month of gestation. Starting from second month, a significant $(\mathrm{p}<0.05)$ decline of serum E2 concentrations was shown in SI and AI group ewes compared with both control group ewes until the end of experiment. In comparison between periods, all group ewes showed gradual significant $(\mathrm{p}<0.05)$ decline of serum E2 concentrations along with the progress of experiment periods.

\section{DISCUSSION}

In the current study, we tried to find out and compare two new techniques for induction of superovulation and to increase the ovulatory rates without using exogenous hormone treatments in Iraqi Awassi ewes during the non-breeding season, which is associated with low fecundity $[2,3]$ as the ewes always failure to conceive during the breeding season.

Increased number of embryos in synthetic inhibin treated (SI) and SFBFF antiserum treated (AI) group ewes shown in the present study, could be attributed to the stimulatory effect 
SI
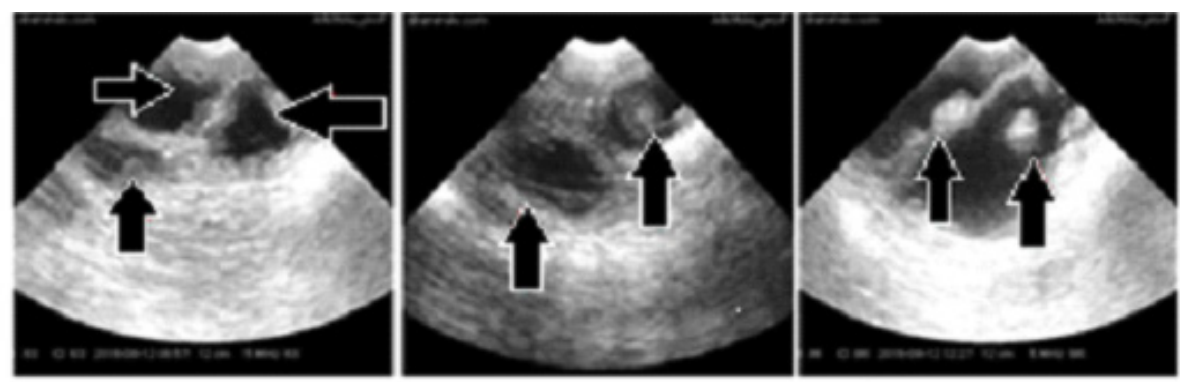

Al
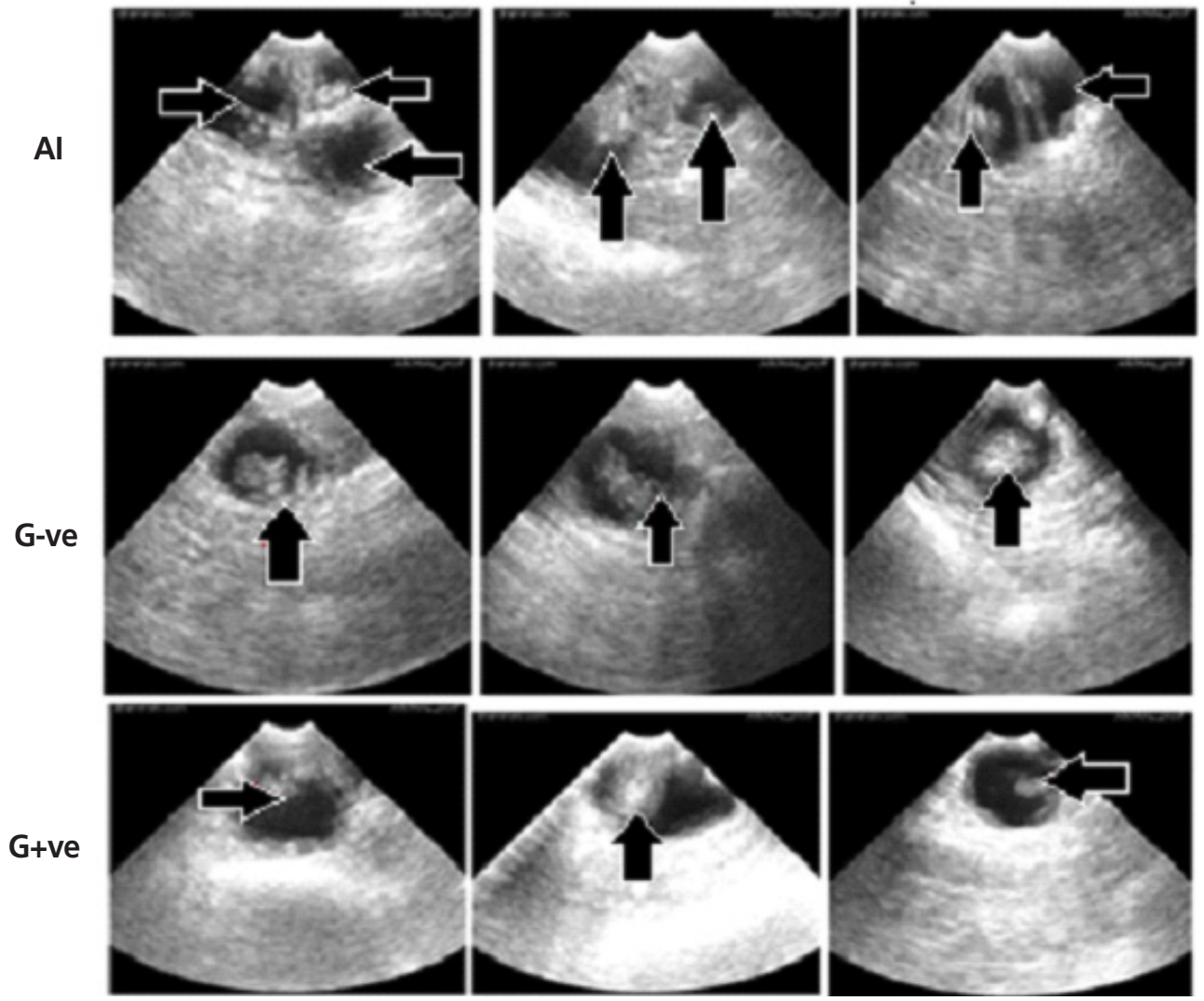

Figure 1. Ultrasonographic images of embryos at day 38 of pregnancy using trans-abdominal examination of Awassi ewes injected, at days 0,28 , and 50 of treatment, with 4, 2, and $2 \mathrm{~mL}$ of normal saline (control; C-ve), 400, 200, and $200 \mu \mathrm{g}$ of ovalbumin (positive control; C+ve), 400, 200, and $200 \mu \mathrm{g}$ of synthetic inhibin (SI group), and $4 \mathrm{~mL}$ of normal saline at day 0, 4, and $2 \mathrm{~mL}$ of SFBFF antiserum, at days 28 and 50 (Al group), respectively. Black arrows refer to embryos.

of inhibin or its immunoneutralization on the ovary, either through an endocrine effect by the suppressing inhibitory action of inhibin and stimulatory action of activin on ovarian gonadotrophs, and subsequently FSH secretion. Our previous studies also demonstrated the stimulatory effect of anti-follicular fluid injection to increase pituitary FSH secretion $[7,8]$. High levels of FSH along with the paracrine and/or autocrine effect of locally produced activins could enhance ovarian follicular development and increasing the number of growing follicles and subsequently the ovulation rates [6-8]. In agreement with our result, Naqvia et al [18] suggested that active immunization of non-prolific Malpura ewes against inhibinbased peptides could increase the ovulatory rate through increasing FSH concentrations. Previous studies also demonstrated elevated plasma FSH concentration in female rats passively immunized against inhibin- $\alpha$ subunit $[19,20]$ and increased the ovulation rate [21].

In this study administration of inhibin or immunization against inhibin either actively or passively has been shown to stimulate the secretion of pituitary FSH as well as ovarian activin and E2 (unpublished data). In comparison with the previous results $[11,12]$, increased pituitary FSH secretion, enhanced multiple follicular development, super-normal ovulation and subsequently increased ovulation rates, produced twin births. These findings agreed with that reported by Bingol et al [22], who used ultrasonographic inspection for diagnosis of pregnancy and determining the number of fetuses, also they found significant high number of $5 \mathrm{~mm}$ follicles developed with subsequent multi ovulation, and an increased number of twin births in ewes actively immunized against 


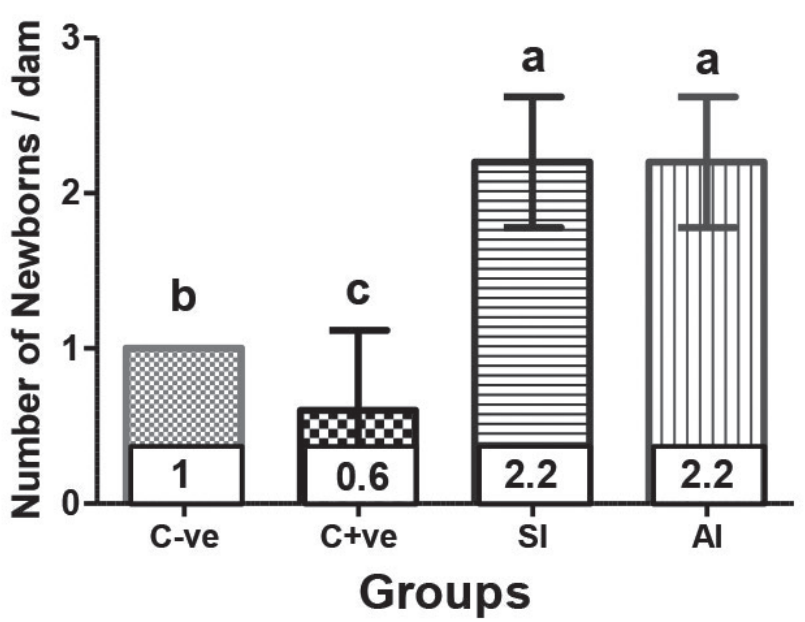

Figure 2. Mean number of newborns per dam in Awassi ewes injected, at days 0,28 , and 50 of treatment, with 4, 2, and $2 \mathrm{~mL}$ of normal saline (control; C-ve), 400,200 , and $200 \mu \mathrm{g}$ of ovalbumin (positive control; C+ve), 400, 200, and 200 $\mu \mathrm{g}$ of synthetic inhibin (SI group), and $4 \mathrm{~mL}$ of normal saline followed by 4 and 2 $\mathrm{mL}$ of steroid free bovine follicular fluid (SFBFF) antiserum (Al group), respectively. The values represented as mean \pm standard deviation. Different letters denote significant difference $(p<0.05)$ between groups.

inhibin a-subunit 1 to 32 compared with control.

It has been found that type of birth had significant effects on body weight in both sexes, where single lambs were heavier than twins and triplets in all cases. This result was in agreement with that reported by Al-Bial et al [23]. In SI and AI group ewes, the twins and triplets born lambs weighed less at birth as compared with singles in control groups, this might be due to the competition between fetuses for nutrient supplied by the placenta from maternal circulation for growth

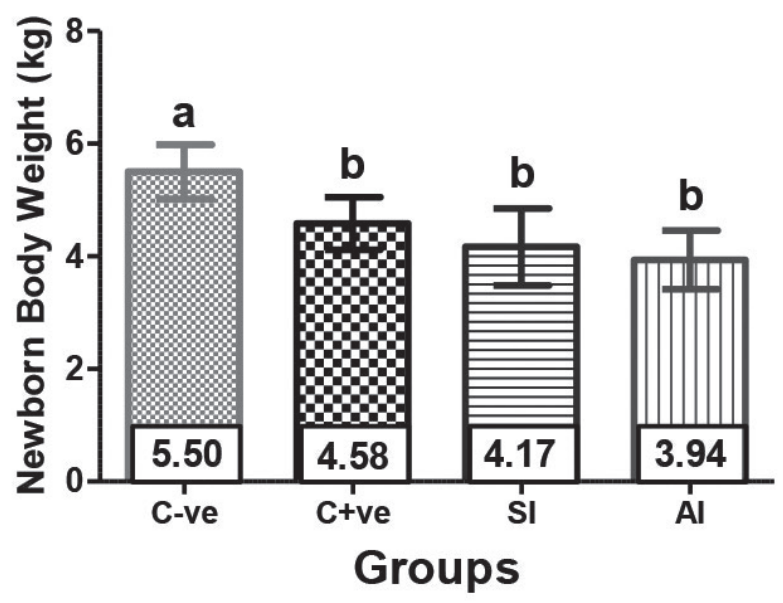

Figure 3. Mean body weight of newborns of Awassi ewes injected, at days 0 , 28 , and 50 of treatment, with 4, 2, and $2 \mathrm{~mL}$ of normal saline (control; C-ve), 400,200 , and $200 \mu \mathrm{g}$ of ovalbumin (positive control; C+ve), 400, 200, and 200 $\mu \mathrm{g}$ of synthetic inhibin (SI group), and $4 \mathrm{~mL}$ of normal saline followed by 4 and 2 $\mathrm{mL}$ of steroid free bovine follicular fluid (SFBFF) antiserum (Al group), respectively. The values represented as mean \pm standard deviation. Different letters denote significant difference $(p<0.05)$ between groups.

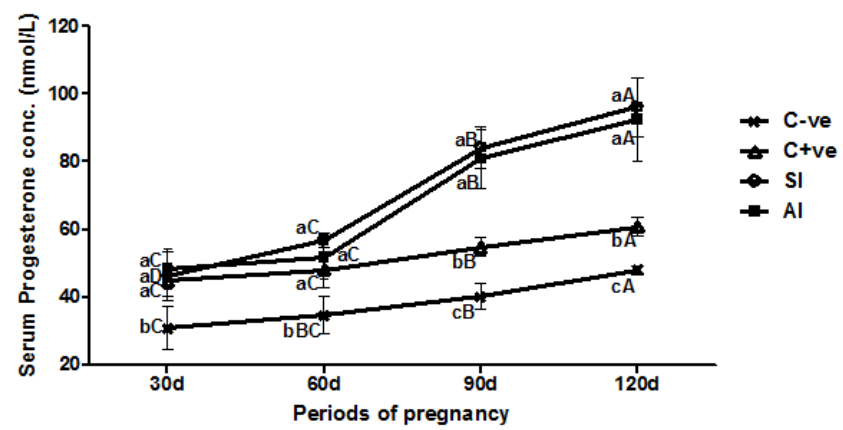

Figure 4. Serum Progesterone concentration (nmol/L) after 30,60, 90, and 120 days of pregnancy in Awassi ewes injected, at days 0, 28, and 50 of treatment, with 4, 2, and $2 \mathrm{~mL}$ of normal saline (control; C-ve), 400, 200, and $200 \mu \mathrm{g}$ of ovalbumin (positive control; C+ve), 400, 200, and $200 \mathrm{~g}$ of synthetic inhibin (SI group), and $4 \mathrm{~mL}$ of normal saline followed by 4 and $2 \mathrm{~mL}$ of steroid free bovine follicular fluid (SFBFF) antiserum (Al group), respectively. The values represented as mean \pm standard deviation. Different small letters denote significant difference $(p<0.05)$ between groups for each period. Different letters denote significant difference $(p<0.05)$ between periods for each group.

due to the low capacity of uteri to provide for twins [24,25].

Regarding the hormonal changes, the present findings showed significant gradual elevation of progesterone concentration throughout the first three months of gestation in all experimental groups, but the elevations in synthetic inhibin treated (SI) and SFBFF antiserum treated (AI) group ewes were significantly higher than that of both control (C-ve and $\mathrm{C}+\mathrm{ve}$ ) group ewes. These differences might be attributed to the increased number of corpora lutea formed from increased number of ovulated follicles during the first month of pregnancy [26], which consequently secreted adequate quantities of progesterone in response to luteinizing hormone (LH) levels. This fact was confirmed by Davies et al [27] who reported a

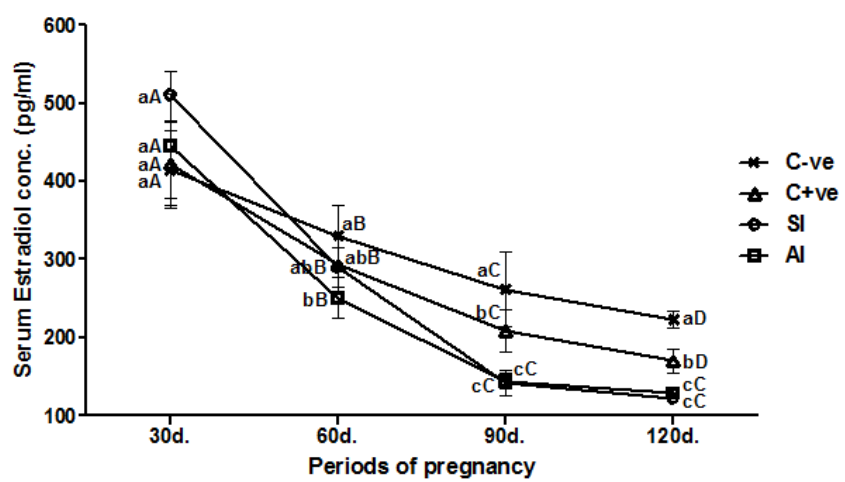

Figure 5. Serum Estradiol concentration ( $\mathrm{pg} / \mathrm{mL}$ ) after 30,60, 90, and 120 days of pregnancy in Awassi ewes injected, at days 0, 28, and 50 of treatment, with 4, 2, and $2 \mathrm{~mL}$ of normal saline (control; C-ve), 400, 200, and $200 \mu \mathrm{g}$ of ovalbumin (positive control; C+ve), 400, 200, and $200 \mu \mathrm{g}$ of synthetic inhibin (SI group), and $4 \mathrm{~mL}$ of normal saline followed by 4 and $2 \mathrm{~mL}$ of SFBFF antiserum (Al group), respectively. The values represented as mean \pm standard deviation. Different small letters denote significant difference $(p<0.05)$ between groups for each period. Different capital letters denote significant difference $(p<0.05)$ between periods for each group. 
positive correlation between serum progesterone levels and the corpus luteum $(\mathrm{CL})$ number in ewe ovaries with different ovulation rates.

Along with the progress of gestation and increased placental development, the ovary will secrete a large quantity of progesterone, which could be attributed to the increased number of embryos [28]. This finding might be supported by Kuznicka et al [29] who found a positive relationship between plasma concentrations of progesterone and the number of ovarian CL or embryos carried as single, twin or triple embryos. In many situations, the level of blood progesterone can be used as an indicator of the ovulation rate in ewes, where lower concentrations are found in single ovulation while higher concentrations occur with twin or triple ovulations [30].

Due to luteinization of ruptured Graffian follicles and absence of new growing follicles, E2 concentrations tend to gradually decline during gestational period [26]. On the other hand, the significant decline of E2 concentrations of SI and AI group ewes might be due to the elevated progesterone which could act via the feedback mechanism on the hypothalamus-pituitary-gonad axis, which prevents secretion of additional amount of FSH and LH, and subsequently no or few ovarian follicle development [29].

\section{CONCLUSION}

It can be concluded that either passive or active immunization against endogenous inhibin have a positive role for increasing FSH secretion, ovarian follicular development and ovulation rats with subsequent augmentation of reproductive fecundity in Iraqi Awassi ewes during non-breeding season. Future studies can be recommended to perform either of the two techniques in the breeding season to augment fecundity and prevent conception failure.

\section{CONFLICT OF INTEREST}

We certify that there is no conflict of interest with any financial organization regarding the material discussed in the manuscript.

\section{ACKNOWLEDGMENTS}

We would like to thank Al-Ataba Al-Abasia Holy/Al-Kafeel company for general investment, Barakat Abulfadhl Station, Kerbala governorate, Iraq, who provided the ewes and allowed us to conduct our study experiments in their fields.

\section{REFERENCES}

1. Al-Salihi KA. An insight into veterinary education in Iraq. (International Development) Vet Rec 2012;171:316-7.
2. Treacher TT. Guidelines for the management of the nutrition of flocks in West Asia during the dry and mating period: what information do we have and what do we need. In: Haddad $\mathrm{N}$, Tutwiler R, Thomson E, editors. Improvement of CropLivestock Integration Systems in West Asia and North Africa. Proceedings of the Regional Symposium on Integrated CropLivestock Systems in Dry Areas of West Asia and North Africa; 1995 Nov 6-8: Amman, Jordan. Aleppo, Syria: ICARDA; 1997.

3. Thompson TB, Woodruff TK, Jardetzky TS. Structure of an ActRIIB: activin a complex reveal a novel binding mode for TGF-beta ligand: receptor interactions. EMBO J 2003;22:155566.

4. Jaber LS, Habre A, Rawda N, et al. The effect of water restriction on certain physiological parameters in Awassi sheep. Small Rumin Res 2004;54:115-20.

5. Al-Khazraji AA, Abu-Tabeigh SM, Abdulkareem TA, Mahdi UA. Reproductive responses of Awassi ewes to different level of PMSG administration. Iraqi J Agric Sci 2000;31:681-7.

6. Al-Sảaidi JAA, Al-Okaily BN, Al-Shwilly HA. Uterine implantations and litter size alteration in anti-inhibin and eCG-hCG treated virgin pregnant female rats. Online Int Interdicip Res J 2016;6:36-46.

7. Al-Sảaidi JAA, Al-Jayashi G. Adenohypophyseal immunohistochemoial expression levels of FSH $\beta$ in cyclic virgin female rats treated with steroid free bovine follicular fluid antiserum. Online Int Interdicip Res J 2016;6:18-31.

8. Al-Saaidi JAA, Majhwol EM. Effect of immunization against steroid-free bovine follicular fluid on reproductive hormones profile in cycling female rats. Asian J Anim Sci 2017;11:183-8.

9. Scaramuzzi RJ, Baird DT, Campbell BK, et al. Regulation of folliculogenesis and the determination of ovulation rate in ruminants. Reprod Fertil Dev 2011;23:444-67.

10. Knight PG, Glister C. Potential local regulatory functions of inhibins, activins and follistatin in the ovary. Reproduction 2001;121:503-12.

11.Li DR, Qin GS, Wei YM, et al. Immunisation against inhibin enhances follicular development, oocyte maturation and superovulatory response in water buffaloes. Reprod Fertil Dev 2011; 23:788-97.

12.Liu YP, Mao XB, Wei YM, et al. Studies on enhancing embryo quantity and quality by immunization against inhibin in repeatedly superovulated Holstein heifers and the associated endocrine mechanisms. Anim Reprod Sci 2013;142:10-8.

13. Wang H, Herath CB, Xia G, Watanabe G, Taya K. Superovulation, fertilization and in vitro embryo development in mice after administration of an inhibin neutralizing antiserum. Reproduction 2001;122:809-16.

14. Kishi H, Okada T, Otsuka M, et al. Induction of superovulation by immunoneutralization of endogenous inhibin through the increase in the secretion of follicle-stimulating hormone in the cyclic golden hamster. J Endocrinol 1996;151:65-75.

15. Takedomi T, Kishi H, Medan MS, et al. Active immunization 
against inhibin improves superovulatory response to exogenous FSH in cattle. J Reprod Dev 2005;51:341-6.

16. Wrathall JHM, McLeod BJ, Glencross RG, Beard AJ, Knight PG. Effects of active immunization against a synthetic peptide sequence of the inhibin $\alpha$-subunit on plasma gonadotrophin concentrations, ovulation rate and lambing rate in ewes. J Reprod Fertil 1992;95:175-82.

17. Tsonis CG, Borchers CE, Hungerford J, et al. Effects on ovulation and lambing rates after immunizing sheep with recombinant inhibin alpha subunit. Proceedings of the 8th Australian Biotechnology Conference; 1989. pp. 444-7.

18. Naqvi SMK, Joshi A, Gulyani R, et al. Active immunization against inhibin-based peptides to increase ovulation rate in non-prolific Malpura ewes. Small Rumin Res 2009;81:163-6.

19. Culler MD, Negro-Vilar A. Passive immunoneutralization of endogenous inhibin: sex related differences in the role of inhibin during development. Mol Cell Endocrinol 1988;58:263-73.

20. Thanoon HB. Hypothalamic GHRH and pituitary GH genes expression levels in sequential neonatal inhibin immunineutralized female rats [MSc Thesis]. Al Diwaniyah, Iraq: AlQadesiyah University; 2013.

21. Rivier C, Vale W. Immunization of endogenous inhibin modifies hormone secretion and ovulation rate in the rat. Endocrinology 1989;125:152-7.

22. Bingol M, Daskiran I, Cedden F, Demir AO, Yilmaz A. Inhibin immunization in Norduz sheep. Arch Tierz 2012;55:179-83.

23. Al-Bial A, Singh J, Singh DP, Niwas R. Environmental and genetic factors on growth traits of Black Bangal sheep in Yemen. Bioscan 2012;7:185-8.

24. Sumaryadi YM, Manalu W. Prediction of litter size based on hormones and blood metabolites concentrations during pregnancy in Javanese Thin Tail ewes. Asian-Australas J Anim Sci 1999;12:682-8.

25. Baneh $\mathrm{H}$, Hafezian H. Effects of environmental factors on growth traits in Ghezel sheep. Afr J Biotechnol 2009;8:2903-7.

26. Hafez ESE, Hafez B. Reproductive cycle in farm animals. Philadelphia PA, USA: Lippincott William \& Wilkins; 2000.

27.Davies KL, Bartlewski PM, Pierson RL, Rawlings NC. Computer assisted image analyses of corpora lutea in relation to peripheral concentrations of progesterone: A comparison between breeds of sheep with different ovulation rates. Anim Reprod Sci 2006;96:165-75.

28. Roy N, Ishwar AK, Mishra SN. Estimation of steroidal hormones in ovine during different stages of pregnancy, Vet Pract 2012;13:93-4.

29.Kuźnicka W, Rant W, Radzik-Rant A, Kunowska-Slósarz M, Balcerak M. The ovulation rate, plasma progesterone and estradiol concentration, and litter size of a local ewe breed kept in a barn vs. those kept under an overhead shelter. Arch Anim Breed 2016;59:145-50.

30. Ranilla MJ, Sulon J, Mantecon AR, Beckers JF, Carro MD. Plasma pregnancy-associeated glycoprotein and progesterone concentrations in pregnant Assaf ewes carrying single and twin lambs. Small Rumin Res 1997;24:125-31. 